\title{
El último estadio de la Historia (Memoria, Rememoración y Bildung: sobre la teoría de la Modernidad en Hegel)*
}

\author{
AGNES HELLER \\ New School for Social Research, New York
}

En el presente artículo la autora se plantea la posibilidad de supervivencia de la modernidad, tal y como Hegel aborda ese más que crucial problema mediante el concepto de Mundo Moderno. Este concepto puede entenderse en tanto que tiempo presente histórico absoluto, el cual lleva implicita la desmemoria histórica, pero asimismo en tanto que continuo hacerse presente que, mediante la filosofía, rememora y dota de significado nuestra experiencia colectiva. La rememoración es el instrumento de la modernidad que se apropia de su pasado para conocer las posibilidades del futuro, y el aliado de la Bildung (edu- cación) que caracteriza a aquellos individuos que todavía pretenden transformar las cosas y afirmar el reconocimiento mutuo como base de la autocomprensión y la comprensión del Otro. Sin embargo, la autora defiende frente a Hegel un poder de rememoración que no cancela la moralidad kantiana, pues una descripción normativa del mundo moderno ya no cuenta con un espíritu absoluto que supera la mera «historia empírica». Este siglo nos ha ofrecido - $y$ todavía ofrece- un horror tan real que no se deja subsumir dentro de ningún sistema que, al fin y al cabo, no sabe distinguir el bien del mal en aras de lo absoluto.

Se han producido numerosos e interesantes comentarios sobre el giro de orientación efectuado por el concepto de Mundo Moderno de Hegel desde la Fenomenologia del Espiritu hasta La Filosofia del Derecho. Sin embargo, mi presente interés por «el último estadio de la historia»' es peculiar en tanto que me permite hacer caso omiso de importantes diferencias entre los dos libros, así como incluir en la discusión respectivamente - sin discriminación ni críticalas lecciones sobre filosofía de la historia, sobre historia de la filosofía, sobre religión y sobre estética.

* Traducción de Sonia F. Arribas.

1 Vorlesungen über die Philosophie der Geschichte, G. F. W. Hegel, Werkausgabe in zwanzig Bänden, Frankfurt, Suhrkamp, 1970, Band XII, p. 524. 
Mis preguntas son sumariamente las que siguen: ideberíamos entender el hegeliano «último estadio de la historia» como un histórico tiempo presente absoluto? ¿Puede la modernidad sobrevivir según el planteamiento de Hegel? ¿Cuáles son las condiciones para la supervivencia o longevidad de la modernidad en el sistema de Hegel? De igual modo, rebasando el pensamiento de Hegel, preguntaría: ison todavía relevantes algunas de estas condiciones? y, finalmente, ¿incorporaría a la lista hegeliana ciertas condiciones muy ahegelianas para la supervivencia del mundo moderno?

Para evitar malentendidos quiero señalar que cuando hablo del cumplimiento o no cumplimiento de las condiciones hegelianas, no tengo en mente si el presente estado empírico de las cosas concuerda o no con el ideal hegeliano del mundo moderno. No quiero reiterar con Fukuyama que aunque la norma no se haya cumplido, en el mundo occidental ya nos hemos acercado a ella, o que incluso el planeta entero se ha embarcado ya en esta aproximación. Fukuyama habla en términos temporales. Si nuestro problema, efectivamente, tuviera que ver únicamente con el tiempo, Hegel estaría de acuerdo con Fukuyama en dejarlo a un lado. Después de todo, siendo eterno el espíritu del mundo, el tiempo no le concierne y, puesto que la aproximación ha comenzado, ta norma está ya en estado de «hacerse presente» ${ }^{2}$. Pero si suponemos que desde Hegel la norma (la idea) se ha transformado, entonces ya no estamos hablando de tiempo, sino de otro absoluto, de otra eternidad, o de muchas, o de ninguna en concreto. Puesto que la idea del mundo se ha transformado, mi pregunta acerca de la relevancia o irrelevancia de las condiciones hegelianas para la supervivencia de la modernidad no es empírica.

Es bien sabido que la filosofia (después del fin de la filosofia), desde Marx a Heidegger, contribuyó significativamente al abandono de la idea hegeliana del mundo moderno. Es igualmente bien sabido que hoy en día muchos pensadores, cntre los que me encuentro, retornan a la descripción normativa de la modernidad de Hegel como la mejor o la más relevante de las descripciones de este tipo ${ }^{3}$. Pero considerar relevante la descripción normativa de la modernidad de Hegel o guardar como una reliquia el sistema hegeliano que dio testimonio de la verdad de esta descripción son dos operaciones completamente diferentes. La cuestión que surge es si es posible aislar el espíritu objetivo de Hegel del espíritu absoluto, cuestión que incluye en realidad dos preguntas: la primera se refiere directamente al filósofo, la segunda indirectamente. En primer lugar, ¿qué puede hacer un pensador poshegeliano y posmetafísico con el «espíritu objetivo»? ¿Hay "espíritu objetivo» sin un conocer absoluto? En segundo término, ¿qué ocurre si la experiencia contemporánea de la (auto)con-

"Este término será aclarado más adelante por la autora, (N. de la T.)

${ }^{3}$ Me quedé asombrada cuando uno de mis estudiantes chinos probó con mucha clocuencia en un trabajo brillante que se puede exponer un argumento mucho más sólido defendiendo la desobediencia civil a partir de la Filosofia del Derecho de Hegel que a partir de la Teoría de la Justicia de Rawls. 
ciencia en general no encuentra ni sentido, ni significado, ni satisfacción en la devoción por y/o el culto del espíritu absoluto (sea en el arte, la religión o la filosofía)? Planteado claramente, y éste será el punto de partida de nuestra ulterior investigación, ino es el modelo hegeliano del mundo moderno una simple hoja muerta sin aquello que su autor denominó reminiscencia (Erinnerung)?

En lo que sigue distinguiré entre "hacerse presente», por un lado, y presente histórico absoluto, por otro. Por «hacerse presente» entiendo el mundo moderno que se puede mantener y rejuvenecer a partir de sí mismo y, en principio (en función de su idea), para siempre. Sin embargo, entiendo por presente histórico absoluto un mundo moderno que se puede mantener, pero no rejuvenecer a sí mismo.

Hegel describe la idea del mundo moderno desde dos enfoques: en la Fenomenologia del Espíritu pone el énfasis en la dinámica de la modernidad, mientras que en La Filosofia del Derecho más bien examina a fondo el orden sociopolítico moderno. No obstante, la Fenomenología también incluye, aunque en pocas palabras, la presentación de este orden moderno, y La Filosofia del Derecho contiene asimismo referencias a la dinámica de la modernidad. Pero tanto si se relata la dinámica moderna cuanto si se estudia a fondo el orden sociopolítico moderno, en uno y otro caso lo que se necesita establecer es lo mismo: la capacidad única que tiene la modernidad de rejuvenecerse mediante su potencial para llevar a cabo contradicciones y para al mismo tiempo reconciliarlas. La modernidad es presentada desde ambas perspectivas como la totalidad de libertades, pudiéndose hablar de una totalidad de libertades cuando ninguna reivindicación de libertad es externa al sistema autorreproductivo. El proceso (que Hcgel denomina Bewegung) mediante el cual queda absorbida una nueva reivindicación de libertad resume la dinámica de la modernidad, mientras que la estructura e interacción de las instituciones dentro de las cuales las libertades son absorbidas es la descripción normativa del orden sociopolítico moderno. Hegel analiza la dinámica de la modernidad bajo el epígrafe de la «moralidad» y su orden sociopolítico bajo el de «eticidad» (Sittlichkeit). Pero tanto la moralidad como la Sittlichkeit poseen un rostro jánico; la moral puede generar Sittlichkeit, pero puede igualmente ponerla en peligro, alterarla. Esto último fue lo que ocurrió en el mundo antiguo, donde la Sittlichkeit ejercía demasiada presión y era demasiado totalizadora como para ofrecer un espacio ideal suficiente para el autodesarrollo de la emergente subjetividad y su reivindicación de libertad. La moderna Sittlichkeit acoge en su seno la moral -aunque sólo con la condición de que los tres «poderes éticos (sittlichen Mächte)» adopten (y preserven) un equilibrio adecuado-. Difícil y frágil equilibrio. 
En la Fenomenología aparece la Sittlichkeit en dos ocasiones: primero en el capítulo «La realización de la autoconciencia racional por sí misma» y, en segundo lugar, en el capítulo sobre el Espíritu ( «El espíritu verdadero, la eticidad»). El brillante segundo capítulo es menos interesante para nuestro presente propósito, pues introduce y analiza la «configuración griega del mundo». Fn el primer caso, en cambio, no tratamos con una "configuración del mundo", sino con una «configuración de la autoconciencia racional», la cual es una «configuración» moderna. Hegel ofrece una especie de análisis del Dasein con una actitud moderna respecto a Grecia, mitad romántica, mitad jacobina, que recuerda sobremanera a Hölderlin ${ }^{4}$. Ésta es una actitud doble: primero lamenta el mundo de la «sustancia ética» que ya no es ni volverá jamás y, sin embargo, extrapola también la Sittlichkeit al futuro, como un mundo que todavía no es, pero que, no obstante, debería ser. Esta figura (o configuración) de la autoconciencia moderna de la Sittlichkeit prepara la base de la moralidad (y no de la Sittlichkeit, tal como expresa Hegel con énfasis) ${ }^{5}$. La moderna Sittlichkeit es examinada primero en la mis-en-scène hegeliana de la Revolución francesa ( La libertad absoluta y el terror»), en su lugar adecuado como una posible «configuración del mundo»: «La obra a que podría arribar la libertad que se da conciencia consistiría en que, como sustancia universal, se hiciera objeto y ser permanente. Ésta sería la diferencia en la libertad, con arreglo a la cual se dividiria en masas espirituales subsistentes y en los miembros de los poderes diversos» ${ }^{6}$. Esta «libertad universal» (posible) hipotéticamente descrita (esto es, el orden sociopolítico propiamente dicho) no es, por supuesto, el mundo de la libertad absoluta.

La dinámica de la modernidad se construye lentamente. Sus condiciones previas son la convicción, la conciencia, el lenguaje y el juicio. El lenguaje aparece aquí como «la mediación entre autoconciencias independientes y reconocidas... la conciencia expresa su convicción» ${ }^{7}\langle\ldots$. [L]a universalidad radica en la forma de la misma... esta forma... es el sí mismo, que como tal es real en el lenguaje, se expresa en él como lo verdadero y precisamente en el lenguaje reconoce todos los sí mismos y es reconocido por ellos ${ }^{3}$. Evidentemente, el mutuo reconocimiento (acknowledgmeni), el igual reconocimiento (acknowledgment), es el punto de partida (y no sólo metafóricamente) de la dinámica de la modernidad, ya que «el lenguaje en que todos se reconocen mutuamente como conciencias escrupulosas, esta igualdad universal, se descompone en la

' En sus Lecciones sobre la estética, Hegel estudia el poema de Schiller Los Dioses de Grecia (y también menciona a Schlegel y Goethe) como la obra representativa que manifiesta la reacción al período del kentendimiento ilustrado». Vorlesungen über die Aesthetik, Werke, Band XVI, pp. 113-114. [Hay traducción castellana de Alfredo Brotóns Muñoz, Lecciones sobre la estética, Madrid, Akal, 1989, pp. 372-374 (N. de la T.).]

'Fenomenologia del Espíritu, trad. de Wenceslao Roces, Madrid, FCE, 7," ed., 1988, pp. 211-214.

"Ibid., pp. 345-346.

"Ibid., p. 380 .

${ }^{8}$ Ibid., p. 381-382. 
desigualdad del ser para sí singular... de este modo, surge necesariamente la oposición de la singularidad contra los otros singulares y contra lo universal, y hay que considerar esta relación y su movimiento» ${ }^{9}$. Esta «consideración» es la descripción de la dinámica de la modernidad. Si el citado conflicto no pudiese acabar en reconciliación mediante el restablecimiento del mutuo reconocimiento, a la modernidad le iría peor que a las épocas precedentes (en lo que atañe a la Sittlichkeit o a la «alienación»). Sería destruida por sus contradicciones internas, pero sin haber transitado todavía a un mundo nuevo; se desmembraría o a la larga se autodestruiría en el furor de una repetición apocalíptica de la absoluta libertad. La cuestión acerca de si hay o no una época después del Apocalipsis, y de si la modernidad tiene alguna posibilidad de sobrevivir, es la que aquí está en juego. Comoquiera que sea, la dialéctica del Mal garantiza la supervivencia de la modernidad, pues el mal es lo particular, lo individual que se hace a sí mismo distinto de lo universal en la acción y en el juicio. El mal (interpretado de esta manera) es el que anuncia algo nuevo (y, como Napoleón, también de vez en cuando algo grande) para el mundo moderno. No obstante, este mal (activo) habla el lenguaje de la igualdad al confesar su «separado ser-para-sí mismo» y estableciendo de esta manera su continuidad con lo universal, con los Otros. Si los Otros lo reconocen, se restablece el igual reconocimiento mutuo, de lo contrario el Otro se convertirá en el «corazón endurecido» y, por consiguiente, en el mal. Y finalmente [se reconocerá como buena esa acción] «a la que la determinación recibida del obrar en el pensamiento llamaba el mal, o más bien da de lado a esta diferencia del pensamiento determinado y a su juicio determinante que es para sí, como lo otro da de lado al determinar de la acción que es para sí» ${ }^{10}$. Según la visión del mundo hegeliana el Mal siempre impulsó la historia hacia adelante, pero en este caso la historia no necesita ningún impulso, puesto que ya habría finalizado. Éste es el motivo por el que el mal, la acción de la separación, de la particularidad, de la negación, del ser-para-sí-mismo, ha de ser superado una y otra vez en el mundo del reconocimiento mutuo (acknowledgment). Hasta aquí todo va bien. Pero no para Hegel, no en esta ocasión. El reconocimiento mutuo presupone indudablemente instituciones de libertad, pero la libertad universal - ya nos hemos referido a esto- no es la libertad absoluta. ¿.Por qué se reconciliarán entre sí (o deberían reconciliarse) los hombres de acción y los hombres de juicio, en lugar de involucrarse en una lucha a vida o muerte, si no es porque Dios en la comunidad los hace perdonar (verzeihen) y reconciliar (versöhnen)"? Esas instituciones han sido imbuidas del Espíritu. El espíritu objetivo de la modernidad ofrece la reconciliación con la realidad, luego es «hacer presente», pero lo es únicamente en la presencia del espíritu absoluto. «El si de la reconciliación», así concluye Hegel el capítulo sobre la moralidad,

Ibid., p. 384.

I" Ibid., p. 391. 
«en que los dos yoes hacen dejación de su ser contrapuesto es el ser allí del yo extendido hasta la dualidad, que en ella permanece igual a sí mismo... es el Dios que se manifiesta en medio de ellos, que se saben como el puro saber» " ${ }^{11}$. La dinámica de la modernidad presupone las modernas instituciones de la Sittlichkeit, pero la emergencia de la moderna Sittlichkeit ya presupone por su parte la dinámica de la modernidad. Como hemos visto, Hegel aludió a esta interacción en el capítulo sobre la libertad absoluta. Y esta dinámica se alimenta del saber absoluto.

La dinámica de la modernidad es el espíritu de la comunidad, puesto que éste es el espíritu de la filosofia. De acuerdo con esto, ningún pensamiento ni ningún juicio es desterrado o excluido de la filosofía, porque aquí todo se reconcilia con todo lo demás. El Dios de la filosofía habita en la moderna comunidad (Gemeinde) —éste es su espíritu-, pues el mundo del espíritu objetivo, independientemente de que sea descrito dinámicamente como moralidad, o estructuralmente como keticidad" (Sittlichkeit), no es tan sólo una especie de dinámica (Bewegung) ni una especie de sistema: es espíritu. El espíritu de esta comunidad que mantiene el mundo moderno «haciéndolo presente».

Puede ser, sin embargo, que esto sea así sólo en la Fenomenología y no en La Filosofía del Derecho. Después de todo, esta última finaliza con la historia del mundo, con la recapitulación del viaje del Espíritu del Mundo, y no con la del espíritu absoluto. No está injustificado, pues, leer a Hegel de la siguiente forma: puesto que la filosofía llegó demasiado tarde (como siempre) y el Pensamiento del mundo apareció solamente «después de que la realidad ha cumplido su proceso de formación y se ha terminado ${ }^{12} \mathrm{y}$, puesto que pinta su gris sobre gris al ocuparse de aquella «configuración» (figura) de vida» que se ha quedado antigua, entonces el «papel» del espíritu absoluto —en tanto que filosofía- se lleva a cabo legitimando el mundo moderno y, particularmente, el Estado moderno. Sin embargo, si leemos el texto de esta manera cl modelo presentado por Hegel no es el modelo para una modernidad que se está «haciendo presente»: una «configuración de la vida antigua» va a desaparecer y su defunción no puede cstar muy lejos. El propio Hegel no excluyó (empíricamente) esta posible conclusión. Por ejemplo, las lecciones sobre filosofía de la religión terminan con las siguientes meditaciones: «Esta disonancia existió en la realidad... Como en tiempos de los Césares romanos... lo divino fue profanado... y ahora también, a causa de que el punto de vista moral, la opinión independiente y la persuasión sin verdad objetiva han adquirido validez, el afán por los derechos privados y por el placer es moneda corriente.» Como resultado, la filosofía tiene que «reconciliarse» con la religión, pero "esta reconciliación en sí misma es meramente parcial, sin universalidad externa;

"lbid., p. 392.

i2 Fundamentos de la Filosofia del Derecho, trad, de Carlos Diaz, Madrid, Libertarias/Prodhufi, 1993, p. 61 . 
la filosofía es en este sentido un santuario apartado y sus sirvientes forman una orden aislada... Cómo encontrará su salida de esta disyuntiva el presente temporal y empírico, cómo se configurará, es algo que se debe dejar a él, y no es ni asunto práctico inmediato ni materia que atañe a la filosofías ${ }^{13}$. La palabra «inmediato (unmittelbar)» está en el texto en cursiva. Aunque los filósofos no son sacerdotes ni la filosofía puede reemplazar la religión en la moderna comunidad, a pesar de todo, la filosofía tiene que estar presente en el «espíritu», pues, de lo contrario, no hay en absoluto espíritu, una vez consumada la desaparición de las religiones tradicionales, incluido el luteranismo.

Cuando Hegel habla acerca de la desaparición de las religiones o, más bien, sobre la reconciliación del contenido de la religión cristiano-luterana con la forma conceptual de la filosofía especulativa, quiere decir que el antiguo Dios está muerto aunque muchos continúen creyendo en Él. Ni la Bewegung (dinámica) de la modernidad, denominada moralidad, ni la autoridad de Dios se reconocen ya como fundamentales. Ninguna de las dos habrán de prevalecer en el espíritu de la comunidad, independientemente del número de sacerdotes. La convicción, la conciencia, el juicio - tanto si justifican fines o deseos privados como si afirman representar algo universal-, los tres operan con conceptos. Así como el mal se justifica a sí mismo con conceptos, de igual mancra la reconciliación será conceptual. El espíritu de la comunidad ha de ser filosófico. Pero la filosofía pinta gris sobre gris en un mundo envejecido y los filosofos no pueden ser sacerdotes. De todo esto podemos concluir, pues, que aunque la filosofía puede comprender el concepto normativo (la idca) dol mundo moderno y aunque en filosofía no hay fracasos, sino sólo victorias, a pesar de esto, cl mundo moderno empírico podría extraviarse de su idea si el mundo objetivo se quedara desprovisto de cspíritu. Ésta es, en efecto, una posibilidad, pero una posibilidad que la filosofía (hegeliana) no puede articular. El espíritu de la religión se ha agotado y los sacerdotes de la filosofía permanecen aparte "para salvaguardar la propiedad de la verdad» " ${ }^{14}$. De acuerdo con Hegel, en la modernidad el Estado es la comunidad en la que habita Dios, pero incluso aunque el mundo de las instituciones resulte ser "positivo", los filósofos, tras la muerte de Dios, tiene aún que «salvaguardar la propiedad de la verdad».

Quisiera defender mi hilo argumental con una lectura tal vez poco ortodoxa de la famosa metáfora de Hegel. Supongamos que dicha metáfora alude al Fausto de Goethe ("Grises son todas las teorías - mas el árbol dorado de la vida es verde- $\rightarrow$ ). La filosofía pinta su gris sobre gris porque recapitula lo que ha sido. Decir lo que el mundo debería ser está más allá de sus competencias. Sin embargo, este pintar gris sobre gris no se yuxtapone al árbol dorado de la vida, pues en el texto ocurre exactamente lo contrario. Hegel

"Vorlesungen über die Philosophie der Religion, Band XVII, pp. 342-344.

ia Ibid. 
califica la filosofía como el «espíritu maduro», maduro está el fruto del árbol dorado de la vida, y añade que la razón estará insatisfecha con la aproximación a la realidad «ni fría ni caliente», o incluso «con fría desesperación». Concluye: «no hay sino que estar en paz con la realidad, cuando es una paz más cálida con la realidad la que el conocimiento asegura» ${ }^{15}$. Por un lado, una configuración de la vida se ha quedado antigua; por otro, la filosofía (que pinta su gris sobre gris) infunde en su cuerpo la calidez de la paz. La metáfora, por tanto, quiere relatarnos lo siguiente: estamos en la última época de nuestra historia del mundo, la filosofia rememora nuestra historia y pinta su gris sobre gris. No obstante, la mismísima filosofía infunde calor a este cuerpo de la modernidad, de forma que el viejo mundo no tendrá que morir, pues no en vano será rejuvenecido a su avanzada edad insuflándole aquel «conocimiento (Erkenntnis)" proporcionado por la filosofía.

Doy por finalizada aquí la introducción. Permítaseme resumir de nuevo el eje central de la argumentación. Hay una diferencia en Hegel (quizá no declarada) entre la idea de mundo moderno que se está «haciendo presente» y una imagen de un mundo moderno que renuncia al espíritu, la cual yo identificaría con el tiempo presente histórico absoluto. El «hacerse presente» de la modernidad es su realidad efectiva, pues la razón es la que «hace presente» en-y-para ella, mientras que un mundo moderno que yo he llamado el presente histórico absoluto podría ser (cn términos hegelianos) real, pero no real efectivo. Esto parece obvio, porque en este presente no existe la razón. Cuando me refiero al presente histórico absoluto, no hablo de un estado de cosas empírico, sino de un ideal de modernidad del cual la rázón en el sentido hegeliano (esto es, el Dios de la comunidad) está ausente. Ausente del concepto mismo.

Por tanto, si regresamos al modelo hegeliano de la modernidad y reiteramos felicitándonos que todo ha salido de la forma en que él dijo que saldría, pagando así (aparentemente) tributo al último filósofo, entonces requeriremos mayor precaución, y no porque se hayan quedado desfasados muchos detalles del modelo hegeliano - menos de los que creemos están efectivamente desfasados-. Por ejemplo, las corporaciones y las propiedades tal y como Hegel las describió ya no existen, sin embargo, ha permanecido el sistema de partidos, el principio de representación. Lo que deberíamos hacer es concentramos en los constituyentes necesarios del modelo hegeliano de la modernidad, que en palabras de Hegel pueden brevemente resumirse: «El principio del mundo moderno es la libertad de la subjetividad, el principio según el cual todos los factores csenciales presentes en el todo intelectual alcanzan ahora sus derechos en el curso de su desarrollo" ${ }^{16}$. Un ideal del mundo moderno que no reconozca el principio de la libertad de la subjetividad como el decisivo no

${ }^{15}$ Fundamentos de la Filosofia del Derecho, prólogo, p. 60.

${ }^{16}$ Hegel's Philosophy of Right, trad. de 'T. M. Knox, Oxford-Nueva York, Oxford University Press, 1952, agregado al parágrafo 273, p. 286. 
evocará el «fin de la historia» del modo en que Hegel lo pensó. Los «poderes éticos» de Hegel son, como es sabido, la familia, la sociedad civil y el Estado, en otras palabras, la comunidad, la socicdad y la superación de ambas. El Estado tiene que ser la encarnación que cohesiona (poder unificador) la Sittlichkeit, no porque Hegel esté obsesionado con aquél, sino porque, de lo contrario, los principios de la comunidad y la sociedad no se pueden poner en equilibrio. Por ejemplo, la idea del «Estado mínimo» es una idea antihegeliana, ya que es la idea del poder que cohesiona la sociedad (civil o no civil) sobre el Estado (y la subjetividad). Este modelo, según Hegel, está a ciencia cierta condenado ${ }^{17}$, aunque no de una manera tan rápida y espectacular como su extremo opuesto, el reino, a más bien el terror del Estado absoluto como absoluta libertad. No hace falta decir que sin la presencia fundamental y fuerte de la familia, la única comunidad moderna, el «poder ético» del Estado no puede ejercer la labor de superación. Si no hay poder ético en la posición de «en sí mismo», entonces no lo hay tampoco en la de "para sí mismo» ni en la de «en-y-para-sí-mismo».

\section{III}

He anticipado la hipótesis de que el siempre reestablecido equilibrio de los poderes éticos (la garantía de la libertad de la infinita intersubjetividad) es el trabajo del espíritu absoluto, o más precisamente, el trabajo de la filosofía. Pero si la filosofía sólo «conoce (erkennt)» ¿cómo puede proveer la energía para el equilibrio? ¿Cómo puede mantener vivo (caliente) el cuerpo de la modernidad? La respuesta de Hegel es sencilla: insuflamos significado proveniente del pasado. En tanto que cl pasado esté en el presente, éste permanece colmado del todo (la totalidad) del espíritu. La filosofía conoce (erkennt) a través de la rememoración (Erinnerung). La rememoración mantiene viva la historia (mantiene vivo, caliente, el cuerpo de la contemporaneidad). Sólo la filosofía puede rememorar, puesto que sólo el pensamiento conceptual puede rememorar aquello que está más allá de nuestra experiencia personal. Dado que el pasado (la historia) está más allá de nuestra experiencia personal (certeza de sentido), la experiencia rememorada siempre es la experiencia de la conciencia (autoconciencia). Lo que la filosofía rememora no es otra cosa que filosofía, o más precisamente, la rememoración de la filosofía por la filosofía significa entender conceptualmente aquello que ya fue comprendido a través del concepto. No es, por tanto, rememoración propiamente dicha. Pero comprender todo aquello que no fue pensamiento conceptual (como el arte antiguo, la religión o el desarrollo de espíritu objetivo) con el pensar, esto sí es reme-

${ }^{7}$ Se podría argüir que el caso de Inglaterra no es analizado por Hegel como una desviación empírica de la idea, pero el modelo está basado en mero raisonnement, reflexión o entendimiento. 
moración. El entero «trabajo» histórico del espíritu (espíritu del mundo y espíritu absoluto) es recordado, recapitulado, repensado y reinterpretado desde el lugar estratégico de su «resultado». Este trabajo constante de la rememoración, sin embargo, no es tan sólo tarea del filósofo, sino que concicrne a todo el mundo, a los ciudadanos, al Volk. Indircctamente, la filosofía alimenta de significado el cuerpo político del presente a todos los niveles. El pasado debe vivir para que el presente viva, y debe vivir en cada individuo y en cada institución.

La rememoración (Erinnenung) tiene poco que ver con la memoria (Gedächtnis) ${ }^{18}$. La memoria también «recuerda hacia atrás», pero recuerda cosas del pasado, recuerda algo externo, trayendo de vuelta lo que no somos. Aspira a conocer sin dar significado. Entre los fragmentos de Hegel de Frankfurt encontramos, por ejemplo, la siguiente anotación: «La memoria es la horca de la que cuelgan estrangulados los dioses griegos... La memoria es el sepulcro, el depósito de lo muerto. Lo muerto yace en ella en cuanto muerto. Está presente en ella como una colección de piedras» ${ }^{19}$. En la Fenomenología, comentando El Sobrino de Rameu, de Diderot, Hegel retorna a la cuestión de la memoria en un contexto histórico bastante concreto. Trata el tema de la Ilustración (mero entendimiento y reflexión) y su relación con la historia. «Una buena mañana, cuyo mediodía no está manchado de sangre si la infección ha calado en todos los órganos de la vida espiritual; solamente la memoria conserva... el modo muerto de la anterior figura del espíritu; y la nueva serpiente de la sabiduría clevada a la adoración sólo se ha despojado así, de un modo indoloro, de una piel ya ajadas ${ }^{20}$. Por supuesto, el relato de Hegel continúa. La mera memoria será negada y pronto superada. Pero hubo, y hay, conceptos de la modernidad que prefieren un tipo de mundo moderno que, como la sabia serpiente, sea capaz de despojarse de todo lo histórico (todas las rememoraciones) como de una piel seca y que sea capaz de vivir simplemente en el presente absoluto. Por ejemplo, asî es como Patrick Diggins resume el legado del pragmatismo americano ${ }^{21}$. De acuerdo con él, el significado de la historia americana es el de suplantarse a sí misma y el de no dejar ninguna huella de tiempo y de tradición. «Según Adam —escribe-en lugar de conducir a la unidad, a la totalidad, al propósito racional y a la dirección consciente, la historia americana se dejó lievar simplemente por la corriente de los acontccimientos... mientras que las ideas tenían pequeña capacidad para configurar una realidad cambiante en la imagen de algún ideal...» ${ }^{22}$. Ésta es la descripción

Indudablemente la rememoración necesita también la memoria.

${ }^{19}$ Escritos de Juventud, ed. de José M. Ripalda, México, FCE, 1. ${ }^{a}$ ed, 1978, p. 167.

* Fenomenologia, p. 321.

2! No todos los pragmatistas americanos se ajustan a este esquema. Pero si se estudia una «institución imaginaria» dominante se puede tomar esta descripción como un punto de partida. El pragmatismo extremo es uel espiritu» de la democracia americana.

"2 J. P. Diggins, The Promise of Pragmatism. Modernism and the Crisis of Knowledge and Authority, Chicago, The University of Chicago Press, 1994. 
de la serpiente de Hegel que se despoja de la historia como de una capa de piel seca. El pragmatismo extremo es indiferente a la «rememoración» y parece como si los Estados Unidos tampoco la necesitaran en absoluto. El último pensador representativo de esta cadena de pensamiento, Rorty, reserva un hueco para la «rememoración» filosófica en la vida privada, pero la excluye de la política, de la vida del Estado. La democracia liberal, sostiene, no necesita la filosofía ${ }^{23}$. Ésta es una idea de la modernidad totalmente antihegeliana, el modelo de un mundo moderno que no tiene tercera dimensión, de un mundo sin pasado. Por lo menos en el sistema hegeliano, el mundo moderno, al carecer de la capacidad de la creatividad (en él no hay nueva filosofía, ni nuevo-granarte, ni nueva religión), sólo puede obtener su espíritu del pasado. El triple significado de la palabra alemana Erinnerung resume genialmente lo que está en juego. Er-innem, en tanto que penetrar profundamente lo interno, significa adquirir la tercera dimensión, Erinnerung, como recuperación de la Entäußerung (enajenación), es cl «hacer presente» de lo temporal (el pasado) y, finalmente, significa también el constante y continuo trabajo de prestar significado a aqucllas cosas que nosotros rememoramos (conceptualmente) y, por tanto, a nosotros mismos. Por supuesto, todas y cada una de las palabras son (objetivamente) una especie de rememoración, ya que el pasado está prescnte en las fibras de cada presente. Sin embargo, la rememoración, sin haber sido comprendida por la conciencia y la autoconciencia, sin un trabajo hermeneutico en desarrollo ejercitado sobre este pasado-en-el-presente, está desprovista del espíritu absoluto, es un mero en-sí-mismo, algo positivo, una hoja seca. Si tomamos el ideal pragmatista de la modernidad tenemos entonces una modernidad que rechaza la rememoración, y la rechaza no sólo empíricamente, sino también normativamente. Denomino este ideal (o norma) la norma o el ideal del presente histórico absoluto. El presente es absoluto aquí, puesto que excluye el trabajo del pasado: es el idcal de un mundo bidimensional y no tridimensional. Si suponemos que este ideal de la modernidad está generalizado en las mentes y que además hunde sus raíces en el mundo empírico de la modernidad, entonces algo completamente diferente del modo hegeliano está a punto de penetrar el mundo moderno. Por supuesto, en este mundo hay conocimiento -pero en tanto que «conocer sobre» (Kennthis) y no qua «conocimiento» (Erkenntnis)- Kenntnis es, como vimos, el asunto de la memoria, no de la rememoración. Es, en el mejor de los casos, conocimiento sin sentido que satisface curiosidad, conocimiento muerte o conocimiento de lo muerto, sin espiritualidad.

El lugar que ocupa la constitución es común a ambas ideas de la modernidad, modernidad como whacer presente» y como presente histórico absoluto. Sin embargo, en el modelo (hegeliano) de la modernidad, el espíritu de la cons-

${ }^{3}$ R. Rorty, Objectivity, Relativism and Thuth, Cambridge, Cambridge University Press, 1991 , pp. $175-176$. 
titución se alimenta de hombres y mujercs de Bildung (traducido normalmente como «educación», término que, no obstante, deja sin traducir todos los matices del original alemán): «la constitución de un determinado pueblo depende en general del modo y de la cultura de su autoconcienciass ${ }^{24}$.

La Bildung es un concepto gencral de Hegel (posee sus particularidades en todos los estadios de la historia del mundo), pero en el modelo de la modernidad describe el camino para que una subjetividad infinita sintetice los potenciales de acción y disfrute de los tres acspacios" de la modernidad en sí misma: el de la familia, el de la sociedad civil y el del Estado. Para aquellos que conciben la sociedad (o cualquier parte de la misma) como una «comunidad», como hacen los comunitaristas, el proceso hegeliano de la Bildung es irrelevante por definición. La Bildung es la tarea de los individuos en tanto que personas privadas, en tanto que ciudadanos de un estado (Staatsbürger). «La finalidad de la razón [es]... que la pasiva ausencia de sí por una parte, y por otra parte la rusticidad del saber y del querer, o sea, la inmediatez e individualidad en las que está hundido el espíritu, sean elaboradas y que en primer lugar esta exterioridad suya reciba la racionalidad de que es capaz, a saber, la forma de la universalidad, la capacidad de entender (Verständigkeit)... La educación es, pues, ... el duro trabajo contra la simple subjetividad del proceder, [mediante el cual] la voluntad subjetiva misma alcanza en sí la objetividad en la que por su parte únicamente la voluntad es digna y capaz de ser la realidad de la idca.» Hegel añade que los «hombres educados» son aquellas personas que «pueden transformar todo lo que los otros hacen en el objeto de la conciencia» ${ }^{25}$.

Ya he mencionado brevemente que el reconocimiento mutuo (Anerkennung) es el verdadero punto de partida de la discusión de Hegel sobre la modernidad. Si todos los scres humanos nacen libres e iguales, la idea del reconocimiento mutuo ya ha aparecido. Pero la dinámica de la modernidad, tal y como la describe Hegel en la Fenomenología, es impulsada por el momentáneo y constantemente repetido desequilibrio en la mutualidad de este reconocimiento, donde el equilibrio se alcanza una y otra vez siempre y cuando cl corazón no esté «endurecido» y responda a la «confesión» del Mal con el buen gesto de la reconciliación. Pero un modelo normativo de la modernidad como cl de $\mathrm{Hegel}$ tiene que presentar asimismo las necesarias condiciones personales y subjetivas de la dinámica que hace que el modelo sea factible. Por medio de la Bildung se satisface esta condición. El corazón no se «endureccrá» si es capaz de y está preparado para comprender lo individual o lo particular que se ha separado momentáneamente de lo universal. Esto implica que el corazón tiene que scr «educado» (gebildet) para comprender, y lo individual, que se ha separado de lo universal, también tiene que ser «educado» (gebildet)

${ }^{24}$ Fundamentos de la Filosofia del Derecho, pat. 274, p. 720.

ts Ibid., par. 187, pp. 623-625. [El agregado es nuestra traducción (N. de la T.).] 
porque únicamcnte las «personas educadas» pueden hacerse comprender. El sistema (y la dinámica) del reconocimiento mutuo funciona con la condición de la mutua disposición para la autocomprensión y para la comprensión del Otro. Éste es el modo de universalidad que Hegel primordialmente tiene en mente cada vez que habla acerca de la moderna Bildung, la universalidad que prepara al habitante del burgo (bungher) para la ciudadanía (citizenship). Dicho claramonte, en Hegel el mutuo reconocimiento no reside en el lenguaje o en el sentido común, sino en la disposición para el uso correcto de este lenguaje que requicre, en primer término, que cada individuo se «trabaje» a sí mismo. La Bildung de Hegel nos recuerda el concepto aristotélico de paideia. «La persona educada" (Der gebildete Mensch) es como una estatua, está bien formada. Pero tanto el dueño de sí mismo como la estatua son la misma persona, ambos son el sujeto y el objeto de la Bildung.

Por tanto, la capacidad de «mantener» el espíritu de la modernidad debe adquirirse mediante un trabajo tenaz en nosotros mismos. La constitución no será más que un trozo de papel en lugar del «Estado interno» repleto de cspíritu, a no ser que la gente de Bildung la mantengan viva, pues los que carecen de Bildung la usan sofística e hipócritamente.

¿Cómo pueden convertirse las personas en personas «educadas» (gebildet)? Desarrollan el compromiso con la constitución, con la vida ética del Estado y con el pueblo (Volk), se entrenan en dar preferencia a éstos frente a sus más estrechos y particularistas fines de utilidad y placer. Desarrollan buenos modales de conducta que ayudan a limar los ásperos bordes de la comunicación del día a día. ¿Qué hace posible que los hombres y mujeres modernos lleven a cabo de buena gana el trabajo para conseguir todo esto? Hegel tiene a mano la respuesta: la rememoración (Erinnening), el pensar, la repetición transcontextual del «resultado» de las aventuras del espíritu. La Bildung no es filosofía. Hegel nos ofrece el siguiente ejemplo: los hombres y las mujeres de Bildung cmplean la cópula en su lenguaje, pero no plantean la pregunta acerca de lo que éste «es» (Ser) realmente es. Los hombres y las mujeres de Bildung no son los sacerdotes de la Verdad, del Conocimiento Absoluto; ellos, por el contrario, se han convertido en personas «educadas» (gebildet) porque han saqueado los tesoros salvaguardados por aquellos sacerdotes.

Quisiera volver al principio. La filosofia hegeliana de la modernidad no puede ser desligada del sistema hegeliano, puesto que el espíritu absoluto es el que garantiza que el modelo pueda funcionar. Se trata de un modelo de una modernidad para gente que participa del espíritu absoluto, la gente enumerada en la filosofía de la historia: para los denominados pueblos históricos del mundo (suponiendo que aún existan), para los chinos, los indios, los judíos, los persas, para todos los europeos. Las gentes que estân haciendo presente un pasado pueden readquirir la tercera dimensión del presente - su kespíritu» siempre puede regresar. 


\section{IV}

Para una mentalidad hcgeliana, el surgimiento en el siglo $\mathrm{xx}$ de los regímenes totalitarios en el corazón de Europa podría atribuirse a las vicisitudes de la mera «historia empírica». Desde una perspectiva histórico-mundial no se puede argüir en contra de esta idea. Después de todo, la historia mundial es el tribunal del mundo y este tribunal acaba de dictar sentencia sobre todos los intentos de saltar sobre Rodas. Hegel es vindicado: si cogemos la rosa de la cruz del presente y nas reconciliamos con la realidad, no penetrará horror alguno en el mundo. Pero el horror ha penetrado ya el mundo y, como todos los acontecimientos empíricos, puede reaparccer. La cuestión es si el modelo normativo hegeliano de la modernidad puede ofrecer a los actores individuales alguna directriz en cuando a la elección y el juicio, siempre que el mundo empírico fracase en la equiparación con la norma. $Y$ si consideramos que el estado empírico de las cosas fracasa siempre en la equiparación con la norma (de la modernidad), aunque no sea de un modo tan extremo y espectacular como en el mundo del totalitarismo, entonces tenemos que inferir que el sistema de Hegel no consigue, ni siquicra aproximadamente, sostén moral fiable alguno para aquellos individuos que actúan y juzgan.

He sostenido hasta ahora que el modelo hegeliano es superior al denominado ideal pragmatista porque una modernidad tridimensional ofrece mayor libertad y más estabilidad que una bidimensional. Pero la conclusión del sistema de Hegel mediante el espíritu absoluto, punto fuerte del modelo, es asimismo la fuente de su mayor debilidad. Esta circunstancia puede darle la vuelta a la tortilla.

Los Estados europeos totalitarios se han servido del poder de la rememoración (Erinnerung) y también han considerado el Estado como el depositario de la Sittlichkeit. Se han legitimado asimismo con [una especie de] Espíritu del Mundo que está más allá de todas las justificaciones particulares. La rememoración no garantiza en sí misma ni la división de poderes ni la libertad de la infinita subjetividad, pero aun en el caso de que ninguno de éstos fuese adquirido, Hegel (al hablar de los antiguos) ve las cosas del siguiente modo: «Pero ningún pueblo... tiene que reconocer un tribunal de conciencia»» «El individuo debe inclinarse ante el poder universal y este poder universal, real y más noble es el pueblo» ${ }^{26}$. La persona que se aísla de este poder universal es mala y el mal sólo puede hacerse bueno retrospectivamente, después de que su posición sea aceptada por el Estado, por el pueblo (Volk). Hegel acusó a Kant de formalismo moral, pero nada es más formalista, en un sentido moral, que el concepto de Mal de Hegel. El contenido del mal/bien es proporcionado

${ }^{2 s}$ Vorlesungen über die Geschichte der Philosophie, Werke, Frankfurt, Suhrkamp Verlag, 1970, Band XVIII, pp. 510.511. 
por el solo conocimiento y este contenido no es moral. En resumidas cuentas: en lugar de haber escrito extensamente acerca de la moralidad, Hegel anula y cancela la moralidad en términos prácticos. Sólo sabe de ética ${ }^{27}$. Lo que denomina Sittlichkeit es la ética de un Estado o de un pueblo; la ética universal y lo que llama moralidad es otro tipo de ética - la ética de la personalidad-. Sin embargo, todas las éticas de la personalidad (incluidas la marxiana y la nietzscheana) son éticas de autorrealización y autodesarrollo, y la autorrealización no es un tema moral (a no ser que aquel que se realiza sea una persona buena y decente). Todos los demás modos de autorrealización son moralmente indiferentes, aun cuando puedan ser pensados en términos éticos con aprobación (o desaprobación). Supongamos que una persona ha escogido potenciar su talento (por ejemplo, como ingeniero) en la máquina destructiva de un Estado totalitario, mientras que otra se ha aislado en una resistencia silenciosa. ¿Qué scría un juicio puramente hegeliano? En tanto que el totalitarismo perdure, en términos hegelianos el que se autorrealiza será el bueno y el que se automargina el malo, mientras que después de la caída del régimen el juicio podría ser legítimamente el opuesto. Cabría decir entonces que la persona que en resistencia silenciosa se aisló de algo que, más tarde, resultó ser malo había sabido de antemano el juicio de la historia. Victrix causa diis placet.

En las diversas críticas de Hegel al concepto de moralidad de Kant hay muchas intuiciones buenas y objeciones relevantes. No obstante, el punto de vista del criticismo de Hegel, la última identificación entre conocimiento y práctica moral, es un fracaso filosófico que aparece en el sistema como si fuera un triunfo. Pensar la absoluteidad del espíritu absoluto ha colocado la rememoración en el punto central del modelo normativo hegeliano del mundo moderno: esto fue, y todavía es, una ventaja filosófica y política. Pero precisamente porque estaba pensando la absoluteidad del espíritu absoluto, que desterró la moralidad propiamente dicha del modelo mismo. Sin embargo, lo que no es más que un mero fracaso en la teoría, es un desastre en la práctica.

¿Es posible pensar conjuntamente el modelo hegeliano del mundo moderno y la filosofía moral kantiana o kierkegaardiana? ¿Y quizás también junto a una especie de mesianismo débil que Derrida ha defendido últimamente frente a un exceso de hegelianismo demasiado autoindulgente? Indudablemente no, si continuamos pensando sistemática o metafísicamente a la antigua usanza, o si señalamos con el dedo a un único responsable de todos los males del mundo (sea la tecnología o la metafísica, por ejemplo). Necesitamos tanto la filosofía espcculativa como la práctica, pero éstas no tienen por qué ser

"Habermas apunta algo similar en su libro Faktizität und Geltung. Acusa a Hegel correctamente de que disolviera la moralidad en la Sittichkeit. Mi interpretación difiere de la de Habermas en el sentido de que, en mi opinión, el concepto de moralidad de Hegel es también un concepto ético y no moral. 
reunidas bajo un mismo techo. Ninguna de las dos puede ser privada, porque ambas penetran el espíritu de nuestras instituciones, aunque de manera distinta y desde perspectivas diferentes. Cabe sostener que la hegeliana descripción normativa del mundo moderno es todavia la más viable de todas ellas; es posible defender, además, que no es el espíritu del mundo, sino el compromiso con eso de que "es mejor sufrir injustamente que cometer injusticia a otros", lo que está por encima de todas las «justificaciones» en conflicto. Podemos mantener, para finalizar, abierto el horizonte de nuestro mundo tanto a la salvación como a la condena, abierto a la línea de tinieblas que no podemos atravesar más allá de Rodas. 